\title{
Enhancing the Electrochemical Performance of Spinel Zinc Stannate by Mixing with Natural Activated Carbon as Energy-Storage Material
}

\author{
M.M. Morad ${ }^{1}$, R.M. AbouShahba' ${ }^{1}$ and M.M. Rashad ${ }^{2}$
}

${ }^{1}$ Chemistry Department, Faculty of Science (Girls), Al-Azhar University, Cairo, Egypt.

${ }^{2}$ Central Metallurgical Research \& Development Institute (CMRDI), Helwan, Cairo, Egypt.

Received: 15 April 2020/Accepted 22 June 2020 / Publication date: 30 July 2020

\begin{abstract}
This paper aims to the evaluation the electrochemical properties of spinel zinc stannate $\left(\mathrm{Zn}_{2} \mathrm{SnO}_{4}\right)$ and the enhancement of this performance by mixing it with different ratios of naturally prepared activated carbon from pomegranate peels, $\mathrm{Zn}_{2} \mathrm{SnO}_{4}$ nano-octahedron-like structure was prepared by facile hydrothermal method using $\mathrm{NaOH}$ as a mineralizer. The resulted powder was then mixed with different ratios of naturally prepared activated carbon. The characterization of the as-prepared $\mathrm{Zn}_{2} \mathrm{SnO}_{4}$ powder revealed a surface area of $49.5 \mathrm{~m}^{2} / \mathrm{g}$. Further morphological, optical and electrochemical properties were analyzed by field emission scanning electron microscope, UV-Vis spectroscopy, and the electrochemical techniques. The as-synthesized $\mathrm{Zn}_{2} \mathrm{SnO}_{4}$ exhibited a specific capacitance of $212 \mathrm{~F}$ $\mathrm{g}^{-1}$ at $1 \mathrm{~A} \mathrm{~g}^{-1}$ while the optimum ratio is $10 \% \mathrm{AC}+90 \% \mathrm{Zn}_{2} \mathrm{SnO}_{4}$ hybrid composite exhibited $558 \mathrm{~F} \mathrm{~g}^{-1}$ at $1 \mathrm{~A} \mathrm{~g}^{-1}$ which means that capacitance of the $\mathrm{Zn}_{2} \mathrm{SnO}_{4}$ improved by mixing with $10 \%$ activated carbon, indicating an outstanding improvement of the electrochemical storage capability with capacitance retention of $87 \%$ after 2000 cycles at a current density of $10 \mathrm{~A} \mathrm{~g}^{-1}$. Meanwhile, the practical asymmetrical hybrid-device results show a specific capacitance value of $48.6 \mathrm{~F} \mathrm{~g}^{-1}$ at $1 \mathrm{~A} \mathrm{~g}^{-1}, \mathrm{E}_{\mathrm{d}}$ of 19.5 Wh kg-1 and $\mathrm{P}_{\mathrm{d}}$ of $1047.7 \mathrm{~W} \mathrm{~kg}^{-1}$ with capacitance retention of $80 \%$ of the initial capacitance after 2000 cycles at a current density of $10 \mathrm{~A} \mathrm{~g}^{-1}$. Overall, these results demonstrate that the enhancement of $\mathrm{Zn}_{2} \mathrm{SnO}_{4}$ behavior was considered with the addition of the activated carbon on the electrochemical performance of the supercapacitor application.
\end{abstract}

Keywords: Naturally activated-carbon; Zinc stannate: Asymmetric hybrid supercapacitors; Energy storage.

\section{Introduction}

Fuel crisis and ecological deterioration have been considered as an important problem, thus most of researchers and countries tend to have a solution to the energy crisis as an alternative solution such as solar energy, wind energy and also the presence of materials in which the energy is stored for a period of time until it is used (Lewis, 2016; Park et al., 2016 and Zuo et al., 2017.) However, electrical energy storage has become one of the important issues which lead to better utilization of sustainable energies in the future. Therefore, in comparison to batteries, supercapacitors (SCs) are the emerging energy storage technology, because of their ability to store and release energy instantaneously, long life, lower cost, and high-power density with excellent cycle stability. SCs have many applications such as electric vehicles, consumer electronics, portable devices, and wherever a burst of energy supply is required (Shah et al., 2018; Guo et al., 2019 and Wang et al., 2019). SCs are used in applications, where the need to store is or release a huge amount of energy in a very short time. Nowadays, SCs are used primarily in hybrid electric vehicles, electric vehicles, fuel cell vehicles, uninterruptible power supplies, and volatile memory backups in personal computers. The further area of SCs use is energy harvesting systems, solar arrays, or wind turbines, where SCs play a supplementary role next to conventional batteries (Libich et al., 2018; Goodenough et al., 2007; Negre et al., 2015; Motlova, 2014; Zhang et al., 2015; Zhang, 2017; Conway and Pell, 2003; Simon and Gogotsi, 2010 ; Naoi and Morita, 2008; Shukla et al., 2012; Zhang et al., 2009; Yu et al., 2013; Lin and Wu, 2011 and Stević, and RajčićVujasinović, 2006). Electrochemical capacitors or ultra-capacitors have many types such as electrochemical double-layer capacitors (EDLCs), Pseudocapacitors, and battery-type SCs. EDLCs store charge either electrostatically or via a non-faradic process, which involves no transfer of charge between the electrode and the electrolyte (Kiamahalleh et al., 2012; Jayalakshmi and Balasubramanian,

Corresponding Author: M.M. Morad, Chemistry Department, Faculty of Science (Girls), Al-Azhar University, Cairo, Egypt. E-mail: monyam19@yahoo.com 
2008). In contrary to, pseudocapacitors which store charges via the faradic process, hence, there is charge transfer between electrode and electrolyte (Iro et al.,2016). Hybrid capacitor combines both types of EDLs and battery-type SCs, the hybrid SCs can achieve higher energy and power densities with good cycling stability by collecting both Faradaic and non-Faradaic processes to store the charges (Tan and Lee, 2013). Most researches today focus on the production or creation of electrodes from high-energy storage materials such as semiconductor oxides. Zinc stannate $\left(\mathrm{Zn}_{2} \mathrm{SnO}_{4}\right)$ is considered an important ternary semiconductor oxide material due to its high electron mobility, high electrical conductivity, low visible light absorption, and attractive optoelectronic properties. $\mathrm{Zn}_{2} \mathrm{SnO}_{4}$ was reported as a potential material in various applications such as solar cells, gas sensors, Li-ion batteries, and photocatalytic applications (Tan et al., 2007; Oh et al., 2014; Wang et al., 2014; Zhu et al., 2017; Wang et al., 2015 ; Qin et al., 2015; Firooz et al., 2010 and Rasoulifard et al., 2016) . During the last decade, various techniques were developed to synthesize $\mathrm{Zn}_{2} \mathrm{SnO}_{4}$ nanoparticles such as thermal evaporation (Wang et al., 2005 and Wang et al., 2004). Sol-gel, (Kurz et al., 2006 and Fu et al., 2002. mechanochemical synthesis (Nikolic et al., 2004.). co-precipitation (An et al., 2015 and Wang et al., 2007). and hydrothermal route (Jaculine et al., 2013 and Rong et al., 2006). The hydrothermal technique provides an effective way to fabricate high purity and well crystallized $\mathrm{Zn}_{2} \mathrm{SnO}_{4}$ phase, also hydrothermal process does not require high reaction temperature which is favorable in the synthesis of $\mathrm{Zn}_{2} \mathrm{SnO}_{4}$ nanoparticles. It is known that $\mathrm{ZnO}$ evaporates easily at high temperature, therefore, techniques work with high temperatures are not valid for $\mathrm{Zn}_{2} \mathrm{SnO}_{4}$ phase synthesis (Ali et al., 2015; Baruah and Dutta, 2011). In this work, the synthesis of $\mathrm{Zn}_{2} \mathrm{SnO}_{4}$ and usage as an electrode material for SC applications are reported. The structural, morphological, surface area, optical properties, and electrochemical properties of $\mathrm{Zn}_{2} \mathrm{SnO}_{4}$ synthesized by the hydrothermal method were studied. The novelty in this work is the preparation of spinel $\mathrm{Zn}_{2} \mathrm{SnO}_{4}$ without any impurities, testing its electrochemical properties as an SC electrode, and improving the electrochemical behavior by forming composites with different percentage of naturally prepared activated carbon with a high surface area which improved energy life storage. This study aims to investigate and evaluate the low-cost electrode materials for SC application, The addition of naturally activated carbon by ratio $10 \%$ to $\mathrm{Zn}_{2} \mathrm{SnO}_{4}$ improved the capacitance value from $212 \mathrm{~F} \mathrm{~g}^{-1}$ at $1 \mathrm{~A} \mathrm{~g}^{-1}$ for blank $\mathrm{Zn}_{2} \mathrm{SnO}_{4}$ to $558 \mathrm{~F} \mathrm{~g}^{-1}$ at $1 \mathrm{~A} \mathrm{~g}^{-1}$ for $10 \% \mathrm{AC}+90 \% \mathrm{Zn}_{2} \mathrm{SnO}_{4}$ hybrid composite which exhibited excellent electrochemical performance with a remarkable specific capacitance with good cycling stability of $87 \%$ capacitance retention after 2000 cycles at a current density of $10 \mathrm{~A} \mathrm{~g}^{-1}$ which improved the electrode energy-storage life.

\section{Material and Method}

\section{Experimental procedures}

\subsection{Preparation of $\mathrm{Zn}_{2} \mathrm{SnO}_{4}$ nanoparticles.}

All the reagents were of analytical grade purchased from Sigma-Aldrich, For the successful synthesis of $\mathrm{Zn}_{2} \mathrm{SnO}_{4}$ nanoparticles, $2.195 \mathrm{~g}$ of $\mathrm{Zn}\left(\mathrm{CH}_{3} \mathrm{COO}\right)_{2} .2 \mathrm{H}_{2} \mathrm{O}$ and $1.128 \mathrm{~g}$ of $\mathrm{SnCl}_{2} .2 \mathrm{H}_{2} \mathrm{O}$ were dissolved in $100 \mathrm{~mL}$ of deionized water separately and then both the solutions were mixed together under constant stirring, followed by dropwise addition of $0.3 \mathrm{M} \mathrm{NaOH}$ (as a mineralizer) solution into the mixture until a white slurry precipitate was formed at $\mathrm{pH} 8$. Then the mixture was transferred into a $200 \mathrm{~mL}$ Teflon coated autoclave and kept at a hydrothermal temperature at $250{ }^{\circ} \mathrm{C}$ for $48 \mathrm{~h}$. After the hydrothermal reaction, the product was washed with deionized water and ethanol several times and dried. Then the sample was calcined at $400{ }^{\circ} \mathrm{C}$ for $1 \mathrm{~h}$.

\subsection{Materials characterization}

The as-prepared $\mathrm{Zn}_{2} \mathrm{SnO}_{4}$ was characterized by powder X-ray diffraction (XRD, Brucker D8 diffractometer) using the $\mathrm{Cu}-\mathrm{K} \alpha(\lambda=1.5406 \AA)$ radiation and secondary monochromator in the range $2 \theta$ from $10^{\circ}$ to $70^{\circ}$ and scan rate of $2^{\circ} \mathrm{min}^{-1}$. The morphologies were characterized by field emission scanning electron microscope (FE-SEM) using a JEOL instrument (JSM -5410, Japan). The chemical compositions and the valence states of the elements were determined by X-ray photoelectron spectroscopy (XPS, thermos scientific) using $\mathrm{Al} \mathrm{K} \alpha$ monochromatized radiation. The specific surface areas were calculated by the Brunauer-Emmett-Teller (BET) method (using Quanta chrome NovaWin - Data Acquisition and Reduction for NOVA instruments C1994-2013, Quanta chrome Instruments version 11.03). 


\subsection{Optical properties}

The optical properties of the prepared $\mathrm{Zn}_{2} \mathrm{SnO}_{4}$ nanoparticle were studied using $\mathrm{UV}$-Vis scanning spectrophotometer. The UV-Vis absorption spectrum was recorded by a UV-Vis-NIR scanning spectrophotometer (Jasco-V-570 Spectrophotometer, Japan) using a $1 \mathrm{~cm}$ path length quartz cell.

\subsection{Electrochemical measurements}

The electrochemical performance was studied using a three-electrode system which involves the active material as a working electrode, a platinum wire as a counter electrode, and a saturated calomel electrode (SCE) as a reference electrode. The electrolyte used was $6 \mathrm{M} \mathrm{KOH}$. The electrochemical data were collected using (Volta lab 40 PGZ 301, Radiometer Analytical, France) at the room temperature, the working electrode was obtained by mixing the prepared active material with carbon black (conductive additive) and Nafion as a binder in a weight ratio of 80:10:10 respectively, then $0.5 \mathrm{~mL}$ of ethanol was added to the mixture to produce a suspended solution. The working electrode was madeup by a drop-casting method in which the suspended solution dropped into nickel foam substrate (NF, Xiamen Tob New Energy Technology Co. LTD, China) with the dimensions of $1 \mathrm{~cm}$ (width), $2 \mathrm{~cm}$ (length), and $1.6 \mathrm{~mm}$ (thickness). For practical simulation, the asymmetric hybrid device was tested in which $90 \% \mathrm{Zn}_{2} \mathrm{SnO}_{4}+10 \% \mathrm{AC}$ electrode was used as a positive electrode and naturally prepared activated carbon as a negative electrode. Activated carbon was prepared from pomegranate peels. Firstly, the peels were carbonized at $850^{\circ} \mathrm{C}$ for $2 \mathrm{~h}$, then crushed with $\mathrm{KOH}$ (4-fold weight for the carbonized sample) after that the resulted carbonized powder was heated in a tubular horizontal furnace at different temperatures and times. Initially, it was heated at $200^{\circ} \mathrm{C}$ for $60 \mathrm{~min}$ with nitrogen flow of $150 \mathrm{~mL} \mathrm{~min}^{-1}$, the temperature was raised to $500^{\circ} \mathrm{C}$ for $60 \mathrm{~min}$, and then also raised to $850^{\circ} \mathrm{C}$ with a heating rate of $5^{\circ} \mathrm{C} \mathrm{min}^{-1}$ for $100 \mathrm{~min}$ (Dobashi et al., 2015). Finally, black powder was obtained and used as a negative electrode. The device was denoted as $\left.\left(90 \% \mathrm{Zn}_{2} \mathrm{SnO}_{4}+10 \% \mathrm{AC}\right) / / \mathrm{AC}\right)$. The electrochemical measurements were performed using cyclic voltammetry (CV), galvanostatic chargedischarge (GCD), and electrochemical impedance spectroscopy (EIS) measurements. The CV measurements were carried out within a potential window of -0.1 to $0.6 \mathrm{~V}$ (vs SCE) at different scan rates from 10 to $200 \mathrm{mV} \mathrm{s}^{-1}$. GCD measurements were tested at different current densities from 1 to 10 $\mathrm{A} \mathrm{g}^{-1}$ within a potential window of 0 to $0.46 \mathrm{~V}$ (vs SCE). The EIS measurements were performed in the frequency range of $100 \mathrm{kHz}$ to $0.01 \mathrm{~Hz}$ using Nyquist plots. The stability test was carried at current density $10 \mathrm{~A} \mathrm{~g} \mathrm{~g}^{-1}$. The specific capacitance $\left(\mathrm{Csp}, \mathrm{F} \mathrm{g}^{-1}\right)$ was then calculated from the GCD results according to the following equation (Abdel-Aal et al., 2019 and Mai et al., 2013).

$\mathrm{Csp}=\frac{2 I \int V d t}{m V^{2}}$

Where I is the applied current (A), $\Delta \mathrm{t}$ is the discharging time (s), $\mathrm{V}$ is the potential window $(\mathrm{V})$ and $\mathrm{m}$ is the mass of active material ( $\mathrm{g}$ ). For the fabrication of the hybrid SC device, the mass ratio of positive and negative electrodes $\left(\mathrm{m}+/ \mathrm{m}^{-}\right)$can be calculated by the following equation (Chen et al., 2016).

$$
\frac{m^{+}}{m^{-}}=\frac{C_{S P}^{-} \Delta V^{-}}{C_{S P}^{+} \Delta V^{+}}
$$

Where Csp (-) and Csp (+) are the capacitances of the negative and positive electrode, respectively, and $\Delta \mathrm{V}^{-}$and $\Delta \mathrm{V}^{+}$are the potential windows of the negative and positive electrode, respectively. The $\mathrm{CV}$ measurements of the device were carried out within a voltage window of 0 to $1.6 \mathrm{~V}$ at different scan rates from 10 to $200 \mathrm{mV} \mathrm{s}^{-1}$. GCD measurements were tested at different current densities from 1 to 10 $\mathrm{A} \mathrm{g}^{-1}$ between voltage windows of 0 to $1.6 \mathrm{~V}$. The energy density (Ed) and power density (Pd) of the device were calculated according to the equations, respectively (Dai, C.-S., et al., 2013 and Kong, D., et al., 2015).

$\mathrm{E}_{\mathrm{d}}=\frac{\mathrm{I} \int \mathrm{V} \mathrm{dt}}{3.6 \times \mathrm{m}}$

$P_{d}=\frac{3600 \times E d}{\Delta t}$ 
Where $E_{d}$ is the energy density $\left(\mathrm{Wh} \mathrm{kg}^{-1}\right)$, $d t$ is the discharge time $(\mathrm{s}), \mathrm{P}_{\mathrm{d}}$ is the power density $\left(\mathrm{W} \mathrm{kg}^{-1}\right)$, and $(\mathrm{V})$ is the operating voltage window of the device.

\section{Results and Discussion}

1. Crystal Structural and morphological of the synthesized spinel $\mathrm{Zn}_{2} \mathrm{SnO}_{4}$ nanoparticle.

From the XRD pattern, Fig. 1a, the peaks positioned at $2 \theta$ of $17.31^{\circ}, 28.62^{\circ}, 33.80^{\circ}, 35.32^{\circ}$, $41.17^{\circ}, 54.44^{\circ}$, and $59.83^{\circ}$ can be indexed to (111), (220), (311), (222), (400), (511) and (440) planes. All the observed diffraction peaks were in good agreement with the standard data of $\mathrm{Zn}_{2} \mathrm{SnO}_{4}$ with spinel cubic structure (JCPDS \#74-2184), which indicates a good crystallization and a single phase of $\mathrm{Zn}_{2} \mathrm{SnO}_{4}$ obtained hydrothermally at $250^{\circ} \mathrm{C}$ for $48 \mathrm{~h}$ at $\mathrm{pH} 8$ followed by calcination at $400{ }^{\circ} \mathrm{C}$ for $1 \mathrm{~h}$. These conditions are appropriate to remove minor phases of $\mathrm{ZnO}$ and $\mathrm{SnO}_{2}$ (Walsh et al., 2009 and Wei and Zhang, 2001). Fig.1b shows the XPS of $\mathrm{O}_{1 \mathrm{~s}}$, a mean peak with a small shoulder at high binding energy side is observed. The OI deconvoluted-peak is attributed to lattice oxygen while $\mathrm{O}_{2}$ is ascribed to surface $\mathrm{O}_{2}, \mathrm{O}, \mathrm{OH}$ groups, and oxygen vacancies. As shown in Fig. 1c, the peaks can be clearly deconvoluted to two peaks at $1021.5 \mathrm{eV}$ and $1044.5 \mathrm{eV}$, which are consistent with the binding energy of $Z n 2 p_{3 / 2}$ and $Z n 2 p_{1 / 2}$. The splitting energy of $23 \mathrm{eV}$ between $Z n 2 p_{3 / 2}$ and $Z n 2 p_{1 / 2}$ is a typical value for $\mathrm{Zn}^{2+}$ in the $\mathrm{Zn}_{2} \mathrm{SnO}_{4}$. Meanwhile, the high-resolution XPS spectra of Sn show two deconvolutedpeaks, $3 \mathrm{~d}_{5 / 2}$ and $\mathrm{Sn} 3 \mathrm{~d}_{3 / 2}$ as shown in Fig. $1 \mathrm{~d}$, which are obviously observed at $486.9 \mathrm{eV}$ and $495.5 \mathrm{eV}$, respectively, which correspond to the $\mathrm{Sn}^{4+}$ (Qin et al., 2015).
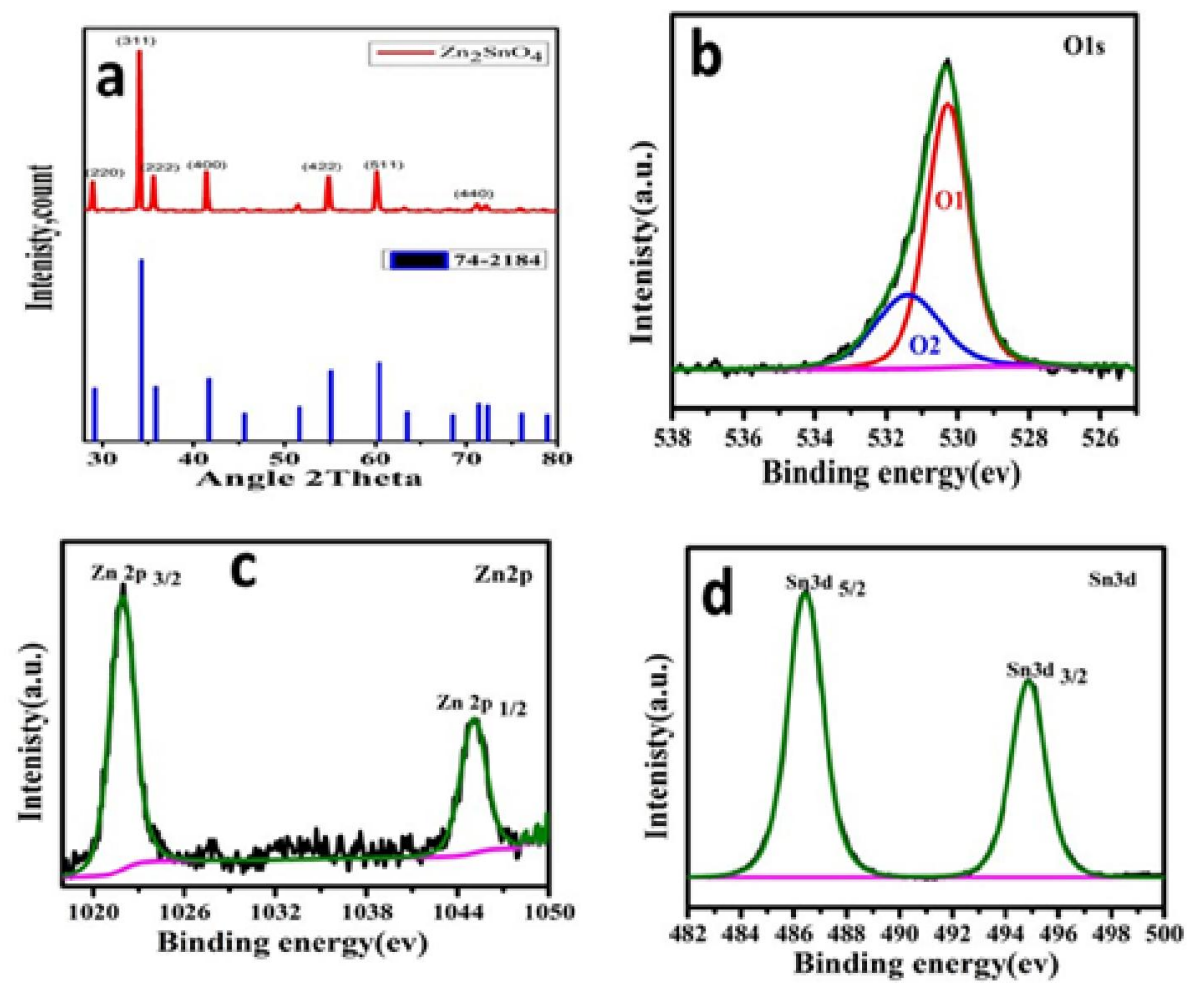

Fig. 1: (a) XRD pattern, and (b, c, d) High-resolution XPS spectra of $\mathrm{Zn}_{2} \mathrm{SnO}_{4}$.

Fig. $2 \mathrm{a}$ and $2 \mathrm{~b}$ reveal the nitrogen adsorption isotherm of the prepared oxide, The BET surface area was calculated from the nitrogen adsorption isotherm in the $\mathrm{P} / \mathrm{P}_{0}$ range from 0.01 to 0.1 at room temperature, the obtained BET surface area is $49.5 \mathrm{~m}^{2} / \mathrm{g}$. The BET curve exhibits the typical type IV isotherms according to the IUPAC classification (Sing, K.S., 1985). Indicating the mesoporous feature of this sample. The average pore diameter is $8.7 \mathrm{~nm}$ (Fig. $2 \mathrm{~b}$ ). 

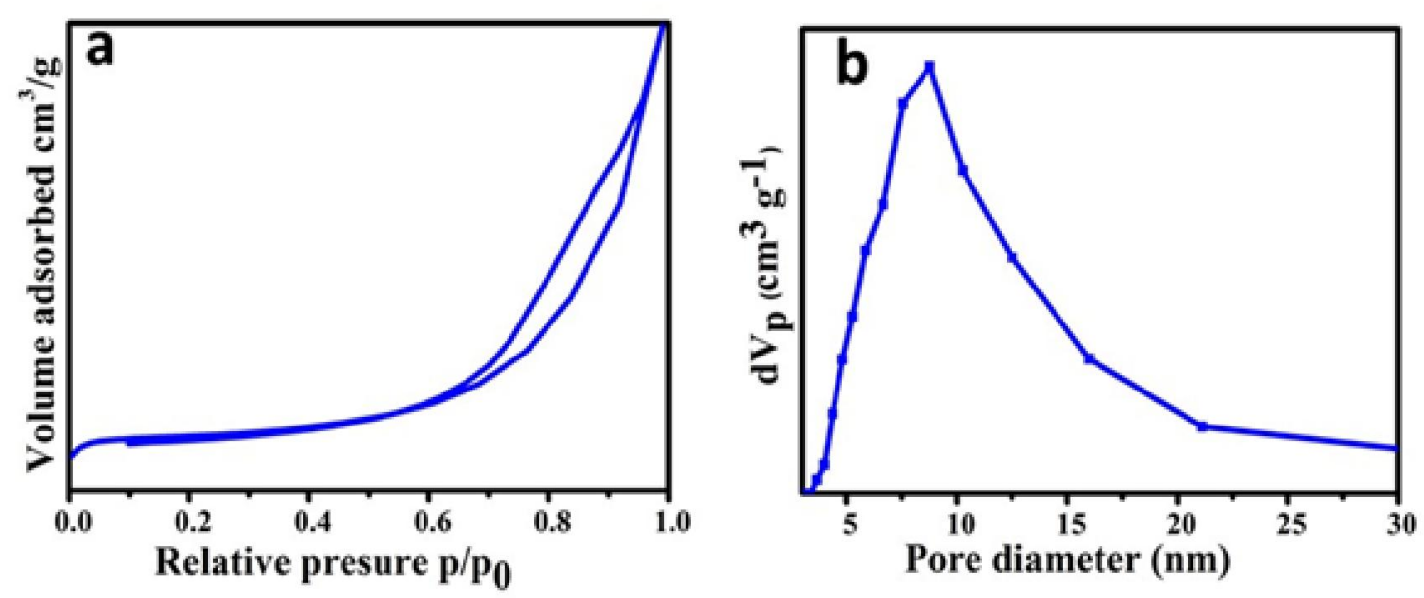

Fig. 2: (a) $\mathrm{N}_{2}$ adsorption-desorption isotherms and (b) pore size distributions of $\mathrm{Zn}_{2} \mathrm{SnO}_{4}$.

Fig.3a shows the FESEM image of the as-prepared $\mathrm{Zn}_{2} \mathrm{SnO}_{4}$, it displays a nano-octahedron-like structure. Fig. 3b, 3c, and 3d show SEM images of different ratios of the composite of natural activated carbon which revealed the formation of octahedron-shaped and some irregular-shaped $\mathrm{Zn}_{2} \mathrm{SnO}_{4}$-activated carbon nanocomposite.
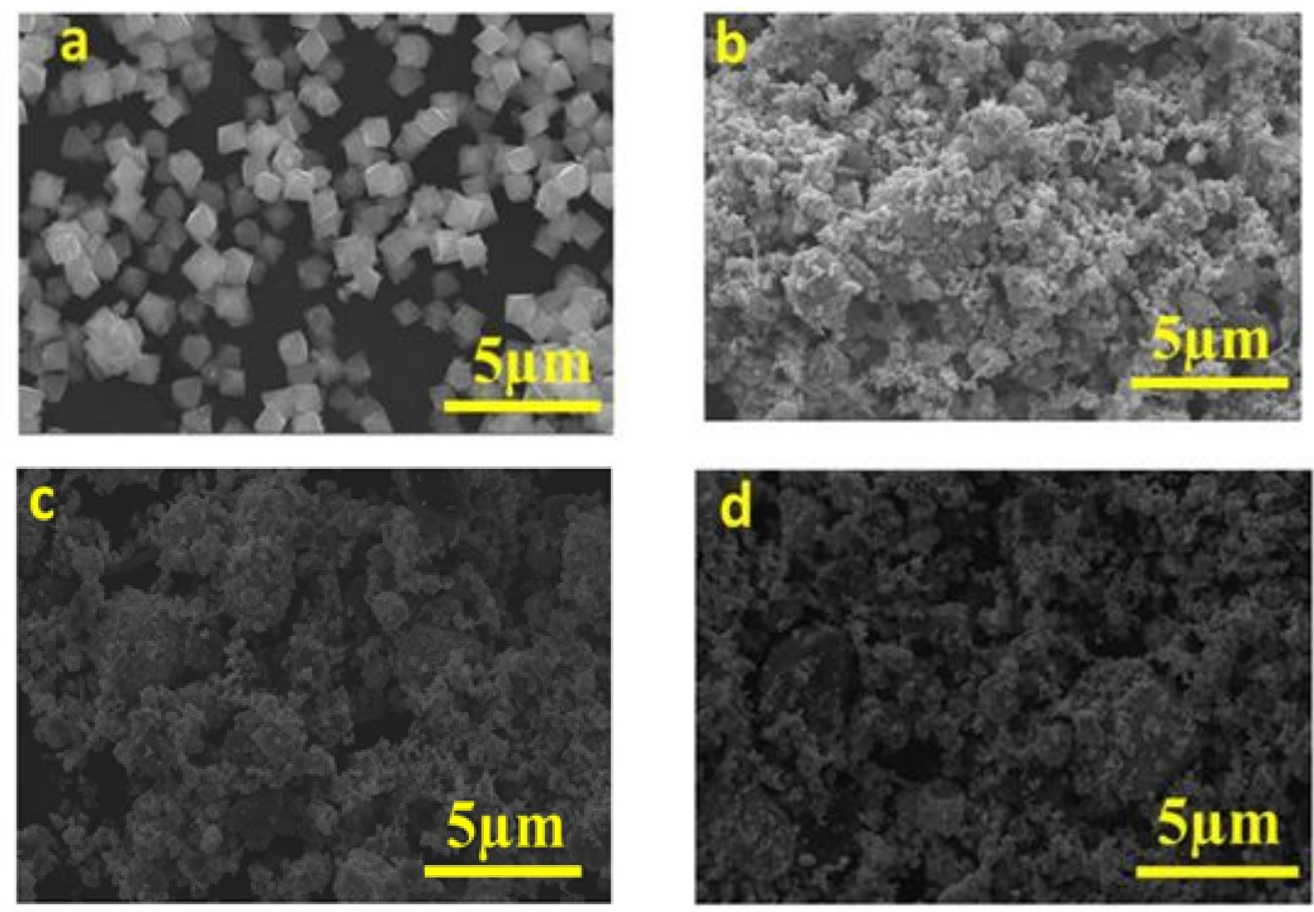

Fig. 3: a) FE-SEM images of the as-prepared $\mathrm{Zn}_{2} \mathrm{SnO}_{4}$ and, (b), (c), (d) for different ratios of $(5,10,15)$ $\%$ Activated carbon mixed with the as-prepared $\mathrm{Zn}_{2} \mathrm{SnO}_{4}$.

\section{Optical properties}

Fig.4a shows the absorption spectrum of the prepared $\mathrm{Zn}_{2} \mathrm{SnO}_{4}$, from the spectrum the maximum absorption was observed at $310 \mathrm{~nm}$, which can be ascribed to $\mathrm{Zn}_{2} \mathrm{SnO}_{4}$. A similar result was observed by Shi and Dai, 2013). It is clearly observed that the $\mathrm{Zn}_{2} \mathrm{SnO}_{4}$ has a steep absorption edge, which indicates that the absorption relevant to the bandgap is due to the intrinsic transition of the semiconductors and not because of the transition from impurity levels (Danwittayakul et al., 2013; Tauc 
et al., 1966). By using the Tauc formula (Coutts et al., 2000) the optical absorption bandgap can be estimated as

$(\alpha h v)^{1 / n}=K(h v-E g)$

Where $\alpha$ is the absorption coefficient, ho is photon energy, $\mathrm{K}$ is a constant corresponds to the material, and $\mathrm{n}$ depends on the nature of transition in a semiconductor. For allowed direct transition $\mathrm{n}=1 / 2$ and for indirect transition $\mathrm{n}=2$, it is known that $\mathrm{Zn}_{2} \mathrm{SnO}_{4}$ is a direct semiconductor and hence, by plotting $(\alpha h v)^{2}$ versus ho the optical band gap, Eg can be determined. Fig. $4 \mathrm{~b}$ shows the Tauc plot for the synthesized $\mathrm{Zn}_{2} \mathrm{SnO}_{4}$, which gives the bandgap $\mathrm{Eg}$ value of $3.16 \mathrm{eV}$ by the intersection of extrapolated linear portion with (hv) x-axis (Coutts et al., 2000; Fu et al., 2009 and Stoimenov et al., 2002). Zeng et al. (2008) have proposed that the fundamental band-gap of $\mathrm{Zn}_{2} \mathrm{SnO}_{4}$ is $3.6-3.7 \mathrm{eV}$ with a direct-forbidden transition, but a heat treatment on $\mathrm{Zn}_{2} \mathrm{SnO}_{4}$ narrows the band-gap to $3.25 \mathrm{eV}$ due to the formation and incorporation of excess $\mathrm{Zn}$ into the $\mathrm{Zn}_{2} \mathrm{SnO}_{4}$ crystal (Zeng et al., 2008). In contrast, Young et al. (2002) have reported the fundamental band-gap of $\mathrm{Zn}_{2} \mathrm{SnO}_{4}$ as $3.35 \mathrm{eV}$, but its bandgap with a high carrier concentration could be widened to $3.89 \mathrm{eV}$ by a Burstein-Moss shift ( Young et al., 2002). Previous papers have reported that the band-gap of $\mathrm{Zn}_{2} \mathrm{SnO}_{4}$ ranges from 3.25 to $3.67 \mathrm{eV}$ (Zeng, et al., 2008 ; Young et al., 2002 ; Zhu et al., 2006 and Cun et al., 2002). Although the optical absorption property of $\mathrm{Zn}_{2} \mathrm{SnO}_{4}$ remains controversial, the estimated band-gap value of our single-crystalline $\mathrm{Zn}_{2} \mathrm{SnO}_{4}$ agrees well with previous reports.
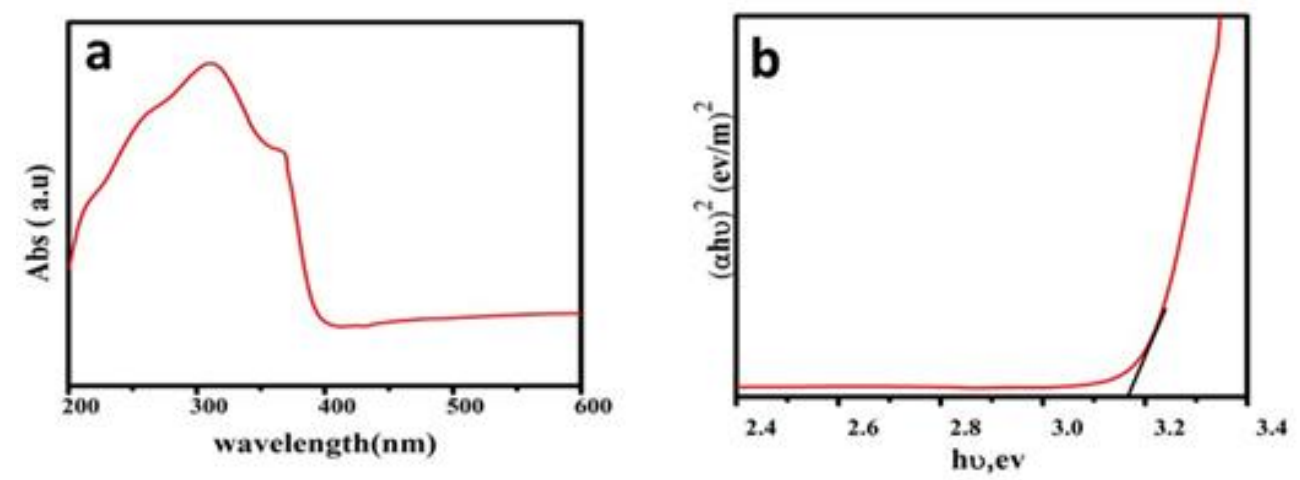

Fig. 4: Please add the figure caption here

\section{Electrochemical performance of the supercapacitor electrodes}

In order to explain electrochemical behavior of the as-prepared $\mathrm{Zn}_{2} \mathrm{SnO}_{4}$ and different ratios $(5,10,15) \%$ of natural prepared activated carbon mixed with the as-prepared $\mathrm{Zn}_{2} \mathrm{SnO}_{4}$ to form a composite as an active electrode material for SCs, the CV, GCD, stability, and EIS were measured in 6 $\mathrm{M} \mathrm{KOH}$, as shown in Figure 5. It can be seen from Figure 5a that the CV plots of different ratios of $\mathrm{Zn}_{2} \mathrm{SnO}_{4}+\mathrm{AC}$ composite and blank $\mathrm{Zn}_{2} \mathrm{SnO}_{4} @ 50 \mathrm{mV} \mathrm{s}^{-1}$ show the presence of well-defined oxidation and reduction peaks suggesting the influence of the faradic reactions in the electrode. For all CV curves, two pairs of redox peaks were noticed within the potential range of -0.1 to $0.6 \mathrm{~V}$ were matched to each other, these redox peaks are assigned to the reversible redox Faradaic-reaction based on the surface reversible redox-reaction mechanism between $\mathrm{Sn}(\mathrm{II})$ and $\mathrm{Sn}(\mathrm{IV})$, which is the principle of the typical characteristic of battery-type behavior, this can be based on the following equation (6) (Jin et al., 2018).

$$
\mathrm{Zn}_{2} \mathrm{SnO}_{4}+\mathrm{OH}^{-}+\mathrm{H}_{2} \mathrm{O}=\mathrm{SnOOH}+2 \mathrm{ZnOOH}+\mathrm{e}^{-}
$$

From CV plots, it is observed that $10 \% \mathrm{AC}+90 \% \mathrm{Zn}_{2} \mathrm{SnO}_{4}$ composite is considered the best ratio with higher capacitance. In order to quantify the discharge specific capacitance, Fig. $5 \mathrm{~b}$ shows the charge-discharge profiles of the prepared $10 \% \mathrm{AC}+90 \% \mathrm{Zn}_{2} \mathrm{SnO}_{4}$ hybrid composite and blank $\mathrm{Zn}_{2} \mathrm{SnO}_{4}$ at current density $1 \mathrm{~A} \mathrm{~g}^{-1}$ in the potential range of 0 to $0.46 \mathrm{~V}$. It is clear that the GCD curves exhibit obvious voltage plateaus, indicating that the supercapacitive performance is a Faradic-type. 
The presence of plateaus in the curves further confirms the existence of a redox reaction, which is consistent with the results obtained from the CV curves. Csp was calculated from GCD measurements according to equation (1), the calculated capacitance values of $10 \% \mathrm{AC}+90 \% \mathrm{Zn}_{2} \mathrm{SnO}_{4}$ hybrid composite and $\mathrm{Zn}_{2} \mathrm{SnO}_{4}$ blank electrodes were $558 \mathrm{~F} \mathrm{~g}^{-1}$ and $212 \mathrm{~F} \mathrm{~g}^{-1}$, respectively, at the current density of $1 \mathrm{~A}$ $\mathrm{g}^{-1}$. The capacitance of the $10 \% \mathrm{AC}+90 \% \mathrm{Zn}_{2} \mathrm{SnO}_{4}$ hybrid composite electrode indicates a super improvement of the electrochemical storage capability by mixing with natural prepared activated carbon, these results were better than obtained in the previous works (Jin et al., 2018 and Dinesh et al., 2016). Fig. 5c also illustrates the effect of different current density on the performance of $10 \% \mathrm{AC}+90 \% \mathrm{Zn}_{2} \mathrm{SnO}_{4}$ hybrid composite electrode, it is clear that all GCD curves exhibit obvious voltage plateaus, further demonstrating the Faradic-type supercapacitive performance. The specific capacitances of $10 \% \mathrm{AC}+90 \% \mathrm{Zn}_{2} \mathrm{SnO}_{4}$ hybrid composite can be calculated from each discharging curve, the calculated values of Csp at different current densities of $1,2,3,4,5$ and $10 \mathrm{~A} \mathrm{~g}^{-1}$ are 559 , $449,398,363,331$ and $265 \mathrm{~F} \mathrm{~g}^{-1}$, respectively. It is clearly observed that the specific capacitance decreases gradually with increasing discharge current density because of the charge storage inhibition of some active sites on the surface of the active material at a high current density (Cai et al., 2016). Fig. 5d illustrates the cycling life which was performed based on GCD measurements, which reveals the cycling stability of $10 \% \mathrm{AC}+90 \% \mathrm{Zn}_{2} \mathrm{SnO}_{4}$ hybrid composite electrode at $10 \mathrm{~A} \mathrm{~g}^{-1}$ for 2000 cycles. Remarkable cycling stability of $10 \% \mathrm{AC}+90 \% \mathrm{Zn}_{2} \mathrm{SnO}_{4}$ hybrid composite is attained with $87 \%$ capacitance retention being stable even after 2000 cycles. EIS was obtained at the open-circuit voltage and the corresponding Nyquist plots are displayed in Fig. $5 \mathrm{f}$.
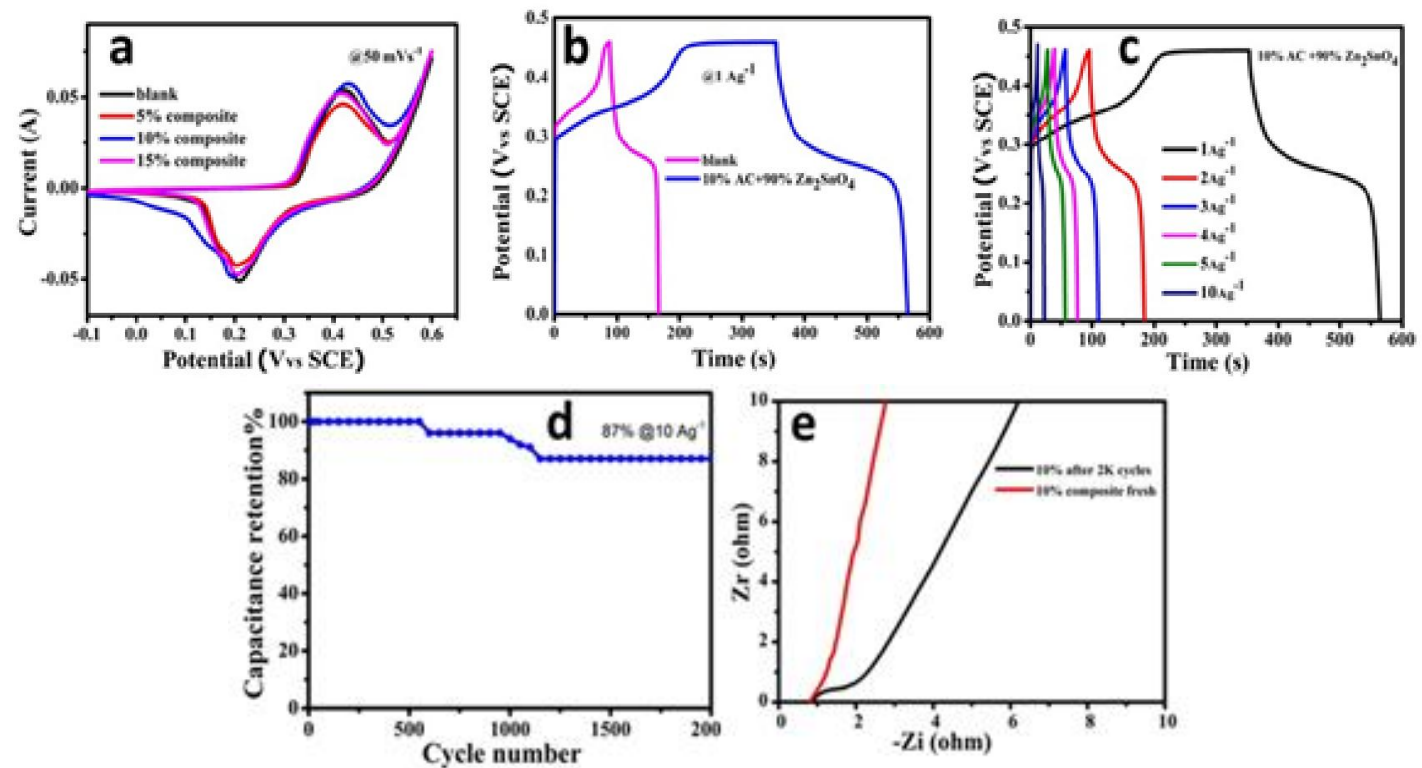

Fig. 5: (a) CV curves at scan rate from $50 \mathrm{mV} \mathrm{s}^{-1}$ (b) GCD at current density $1 \mathrm{~A} \mathrm{~g}^{-1}$ for blank $\mathrm{Zn}_{2} \mathrm{SnO}_{4}$ and $10 \%$ composite (c) Cycling stability of at a current density of $10 \mathrm{~A} \mathrm{~g}^{-1}$, and (d) EIS profile of $10 \%$ composite electrode.

At the high-frequency region, the intersection of the curve at real part $(\mathrm{Zr})$ represents the equivalent series resistance (ESR), which is related to ionic resistance of the electrolyte, internal resistance of the electrode active material, and the contact resistance between the electrode and the current collector (Ito et al., 2015) . From the plots, $10 \% \mathrm{AC}+90 \% \mathrm{Zn}_{2} \mathrm{SnO}_{4}$ hybrid composite as a fresh electrode shows the value of ESR $(0.88 \mathrm{ohm})$ lesser than the one after stability test $(0.97 \mathrm{ohm})$, indicating the absence of the Ohmic loss upon cycling due to high conductivity of AC electrode. The Nyquist plots show a semicircle in the high-frequency region and a near-vertical line at low frequency. The near-vertical line in the lowfrequency region indicates the good capacitive-behavior of the $10 \% \mathrm{AC}+90 \% \mathrm{Zn}_{2} \mathrm{SnO}_{4}$ hybrid composite electrode. 


\section{Asymmetric (hybrid) practical device tested.}

Asymmetric-device was tested in a $6 \mathrm{M} \mathrm{KOH}$ electrolyte using two-electrodes configuration, $10 \% \mathrm{AC}+90 \% \mathrm{Zn}_{2} \mathrm{SnO}_{4}$ hybrid composite as a positive electrode and naturally prepared $\mathrm{AC}$ as a negative electrode. To estimate the capacitance of this device, the mass ratio of the positive and negative electrode materials is 3.5 according to the mass balance equation (Eq. 2) (Csp (+) was calculated from the GCD profile (Fig. 5b). The operation potential of the prepared device can be considered as the sum of the potential windows of $10 \% \mathrm{AC}+90 \% \mathrm{Zn}_{2} \mathrm{SnO}_{4}(-0.1$ to $0.6 \mathrm{~V})$ and $\mathrm{AC}(-1$ to $0 \mathrm{~V})$, therefore, an operation potential window of 0 to $1.7 \mathrm{~V}$ was used. The $\mathrm{CV}$ curves recorded at different scan rates from $10 \mathrm{mV} \mathrm{s}^{-1}$ to $200 \mathrm{mV} \mathrm{s}^{-1}$ for asymmetric $\mathrm{SC}$ in the potential range of 0 to $1.7 \mathrm{~V}$ are shown in Figure $6 \mathrm{a}$. As shown in Fig. 6a in all CV curves of the asymmetrical device presents the redox peaks that were still noticeable in all CV curves, indicating the Faradic-type (battery-like) behavior of the $10 \% \mathrm{AC}+90 \% \mathrm{Zn}_{2} \mathrm{SnO}_{4}$ composite//AC hybrid device. As shown in Fig. 6b, GCD measurements of the device were performed at different current densities of $1,2,3,4,5,10 \mathrm{~A} \mathrm{~g}^{-1}$, The nonlinear chargedischarge profile additionally indicates the battery-type behavior. The device result shows a specific capacitance value of $48.6 \mathrm{~F} \mathrm{~g} \mathrm{~g}^{-1}$, Ed of $19.5 \mathrm{Wh} \mathrm{kg}^{-1}$ and $\mathrm{Pd}$ of $1047.7 \mathrm{~W} \mathrm{~kg}^{-1}$ at a current density of $1 \mathrm{~A}$ $\mathrm{g}^{-1}$. The cycling stability of the as-fabricated hybrid device was performed by repeating the GCD test within 0 to $1.7 \mathrm{~V}$ at a current density of $10 \mathrm{~A} \mathrm{~g}^{-1}$. As shown in Fig. $6 \mathrm{c}$, the hybrid device of $10 \% \mathrm{AC}+90 \%$ $\mathrm{Zn}_{2} \mathrm{SnO}_{4}$ composite /AC exhibits stability of $80 \%$ capacitance retention of the initial capacitance after 2000 cycles, indicating the worthy reversibility and stability of the hybrid device. EIS was also conducted, as shown in Fig. 6d, which showed a lower ESR (1.3 Ohm).
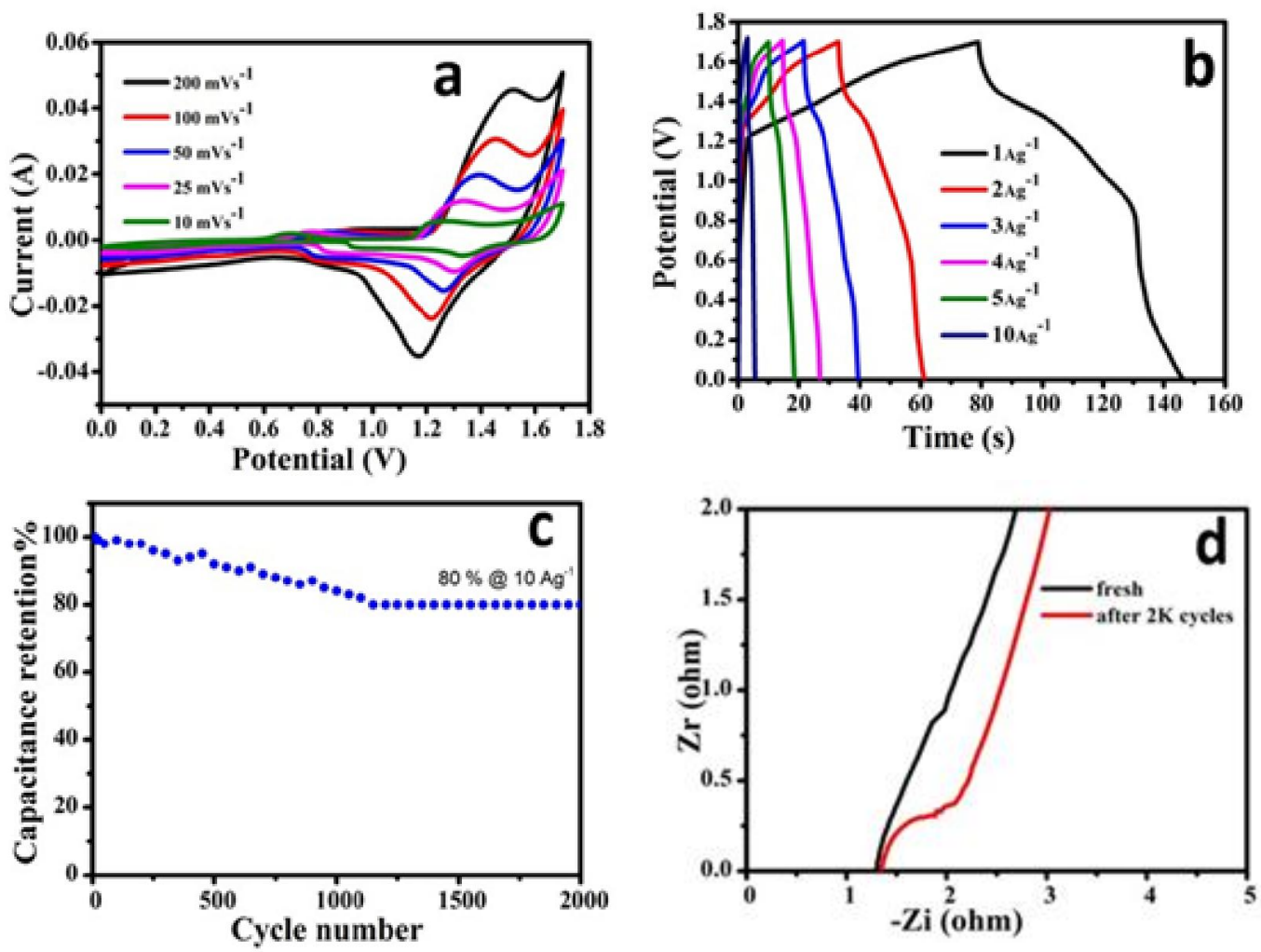

Fig. 6: Electrochemical performance of the $10 \% \mathrm{AC}+90 \% \mathrm{Zn}_{2} \mathrm{SnO}_{4}$ composite //AC hybrid device (a)

$\mathrm{CV}$ curves at different scan rates, (b) GCD curves at different current densities, (c) cycling performance at a current density of $10 \mathrm{~A} \mathrm{~g}^{-1}$ and (d) EIS for the fresh device and after $2 \mathrm{~K}$ cycles.

It was observed that ESR slightly changed (1.4 Ohm) after 2000 cycles, indicating a negligible Ohmic loss upon cycling. Finally, Electrochemical results indicate that the $10 \% \mathrm{AC}+90 \% \mathrm{Zn}_{2} \mathrm{SnO}_{4}$ composite //AC hybrid device working as a battery-type $\mathrm{SC}$ and has great potential as energy-storage material. 


\section{Conclusion}

In summary, due to the good conductivity of the naturally prepared $\mathrm{AC}$ and high capacitive $\mathrm{Zn}_{2} \mathrm{SnO}_{4}$, a different ratio of $\mathrm{Zn}_{2} \mathrm{SnO}_{4} / \mathrm{AC}$ composites are successfully prepared by well mixing. The prepared $\mathrm{Zn}_{2} \mathrm{SnO}_{4}$ obtains a specific capacitance value of $212 \mathrm{~F} \mathrm{~g}^{-1}$ at $1 \mathrm{~A} \mathrm{~g}^{-1}$ while the optimum ratio is $10 \% \mathrm{AC}+90 \% \mathrm{Zn}_{2} \mathrm{SnO}_{4}$ hybrid composite exhibits $558 \mathrm{~F} \mathrm{~g}^{-1}$ at $1 \mathrm{~A} \mathrm{~g}^{-1}$ which indicates the capacitance of the $\mathrm{Zn}_{2} \mathrm{SnO}_{4}$ improved by mixing with $10 \%$ activated carbon, indicating a super improvement of the electrochemical storage capability with capacitance retention of $87 \%$ after 2000 cycles at a current density of $10 \mathrm{~A} \mathrm{~g} \mathrm{~g}^{-1}$. Meanwhile, the practical simulation of asymmetrical hybrid device results shows specific capacitance value of $48.6 \mathrm{~F} \mathrm{~g}^{-1}$, Ed of $19.5 \mathrm{Wh} \mathrm{kg}^{-1}$ and Pd of $1047.7 \mathrm{~W} \mathrm{~kg}^{-1}$ at a current density of $1 \mathrm{~A} \mathrm{~g} \mathrm{~g}^{-1}$, with capacitance retention of $80 \%$ of the initial capacitance after 2000 cycles at a current density of $10 \mathrm{~A} \mathrm{~g}^{-1}$, from this results $\mathrm{Zn}_{2} \mathrm{SnO}_{4}$ with a nano-octahedron-like structure loaded with $\mathrm{AC}$ could be used for high-performance SCs application.

\section{References}

Abdel-Aal, S.K., S.Y. Attia and S.G. Mohamed, 2019. Facile Synthesis of Mn 3 O 4-rGO Nanocomposite as an Efficient Electrode Material for Application in Supercapacitors. Journal of Electronic Materials, 48(8): 4977-4986.

Ali, M.B., et al., 2015. Hydrothermal synthesis, phase structure, optical and photocatalytic properties of $\mathrm{Zn} 2 \mathrm{SnO} 4$ nanoparticles. Journal of colloid and interface science, 457: 360-369.

An, D., et al., 2015. Synthesis of $\mathrm{Zn} 2 \mathrm{SnO} 4$ via a co-precipitation method and its gas-sensing property toward ethanol. Sensors and Actuators B: Chemical, 213: 155-163.

Baruah, S. and J. Dutta, 2011. Zinc stannate nanostructures: hydrothermal synthesis. Science and technology of advanced materials, 12(1): 013004.

Cai, G., et al., 2016. Ultra-large optical modulation of electrochromic porous WO 3 film and the local monitoring of redox activity. Chemical science, 7(2): 1373-1382.

Chen, T., et al., 2016. All-solid-state high performance asymmetric supercapacitors based on novel MnS nanocrystal and activated carbon materials. Scientific Reports, 6: 23289.

Conway, B. and W. Pell, 2003. Double-layer and pseudocapacitance types of electrochemical capacitors and their applications to the development of hybrid devices. Journal of Solid State Electrochemistry, 7(9): 637-644.

Coutts, T.J., et al., 2000. Search for improved transparent conducting oxides: A fundamental investigation of $\mathrm{CdO}, \mathrm{Cd} 2 \mathrm{SnO}_{4}$, and $\mathrm{Zn}_{2} \mathrm{SnO}_{4}$. Journal of Vacuum Science \& Technology A: Vacuum, Surfaces, and Films, 18(6): 2646-2660.

Cun, W., et al., 2002. Synthesis, characterization and photocatalytic property of nano-sized $\mathrm{Zn} 2 \mathrm{SnO}$ 4. Journal of Materials Science, 37(14): 2989-2996.

Dai, C.-S., et al., 2013. Hierarchically structured Ni3S2/carbon nanotube composites as high performance cathode materials for asymmetric supercapacitors. ACS applied materials \& interfaces, 5(22): 12168-12174.

Danwittayakul, S., et al., 2013. Enhancement of photocatalytic degradation of methyl orange by supported zinc oxide nanorods/zinc stannate $(\mathrm{ZnO} / \mathrm{ZTO})$ on porous substrates. Industrial \& Engineering Chemistry Research, 52(38): 13629-13636.

Dinesh, S., et al., 2016. Effect of activated carbon on electrochemical and photocatalytic performance of hydrothermally synthesized zinc stannate nanoparticles. Journal of Materials Science: Materials in Electronics, 27(12): 12786-12795.

Dobashi, A., et al., 2015. Preparation of activated carbon by $\mathrm{KOH}$ activation from amygdalus pedunculata shell and its application for electric double-layer capacitor. Electrochemistry, 83(5): 351-353.

Firooz, A.A., et al., 2010. High photocatalytic activity of $\mathrm{Zn}_{2} \mathrm{SnO}_{4}$ among various nanostructures of $\mathrm{Zn}_{2} \mathrm{XSn}_{1}-\mathrm{xO}_{2}$ prepared by a hydrothermal method. Chemical engineering journal, 165(2):735739.

Fu, G., et al., 2002. Humidity sensitive characteristics of Zn2SnO4-LiZnVO4 thick films prepared by the sol-gel method. Sensors and Actuators B: Chemical, 81(2-3): 308-312.

$\mathrm{Fu}$, X., et al., 2009. Hydrothermal synthesis, characterization, and photocatalytic properties of $\mathrm{Zn}_{2} \mathrm{SnO}_{4}$. Journal of Solid State Chemistry, 182(3): 517-524. 
Goodenough, J.B., H. Abruna, and M. Buchanan, 2007.Basic research needs for electrical energy storage. in Report of the basic energy sciences workshop for electrical energy storage.

Guo, Y., et al., 2019. Functional Hydrogels for Next-Generation Batteries and Supercapacitors. Trends in Chemistry,

Iro, Z.S., C. Subramani, and S. Dash, 2016. A brief review on electrode materials for supercapacitor. Int. J. Electrochem. Sci., 11(12): 10628-10643.

Ito, Y., et al., 2015. High catalytic activity of nitrogen and sulfur co-doped nanoporous graphene in the hydrogen evolution reaction. Angewandte Chemie International Edition, 54(7): 2131-2136.

Jaculine, M.M., C.J. Raj and S.J. Das, 2013. Hydrothermal synthesis of highly crystalline Zn2SnO4 nanoflowers and their optical properties. Journal of Alloys and Compounds, 577: 131-137.

Jayalakshmi, M. and K. Balasubramanian, 2008. Simple capacitors to supercapacitors-an overview. Int. J. Electrochem. Sci, 3(11): 1196-1217.

Jin, K., et al., 2018. $\mathrm{Zn}_{2} \mathrm{SnO}_{4} /$ activated carbon composites for high cycle performance supercapacitor electrode. Journal of Alloys and Compounds, 767: 419-423.

Kiamahalleh, M.V., et al., 2012. Multiwalled carbon nanotubes based nanocomposites for supercapacitors: a review of electrode materials. Nano, 7(02): 1230002.

Kong, D., et al., 2015. Three-dimensional Co3O4@C@Ni3S2 sandwich-structured nanoneedle arrays: towards high-performance flexible all-solid-state asymmetric supercapacitors. Journal of Materials Chemistry A., 3(31): 16150-16161.

Kurz, A., et al., 2006. Strategies for novel transparent conducting sol-gel oxide coatings. Thin Solid Films, 502(1-2): 212-218.

Lewis, N.S., 2016. Research opportunities to advance solar energy utilization. Science, 351(6271): aad1920.

Libich, J., et al., 2018. Supercapacitors: Properties and applications. Journal of Energy Storage, 2018. 17: 224-227.

Lin, Y.P. and N.L. Wu, 2011. Characterization of $\mathrm{MnFe}_{2} \mathrm{O}_{4} / \mathrm{LiMn}_{2} \mathrm{O}_{4}$ aqueous asymmetric supercapacitor. Journal of Power Sources, 196(2): 851-854.

Mai, L.Q., et al., 2013. Synergistic interaction between redox-active electrolyte and binder-free functionalized carbon for ultrahigh supercapacitor performance. Nature communications, 4(1): $1-7$.

Motlova, D., 2014. Aplikace elektroanalytickych metod ve studiu purinovych derivatu. Masarykova univerzita, Prirodovedecka fakulta.

Naoi, K. and M. Morita, 2008. Advanced polymers as active materials and electrolytes for electrochemical capacitors and hybrid capacitor systems. The Electrochemical Society Interface, 17(1): 44-48.

Negre, L., et al., 2015. Solvent-free electrolytes for electrical double layer capacitors. Journal of the Electrochemical Society, 162(5): A5037-A5040.

Nikolic, N., Z. Marinkovic, and T. Sreckovic, 2004. The influence of grinding conditions on the mechanochemical synthesis of zinc stannate. Journal of materials science, 39(16-17): 52395242.

Oh, L.S., et al., 2014. Zn2SnO4-based photoelectrodes for organolead halide perovskite solar cells. The Journal of Physical Chemistry C, 118(40): 22991-22994.

Park, M., et al., 2016. Material design and engineering of next-generation flow-battery technologies. Nature Reviews Materials, 2(1): 1-18.

Qin, L., et al., 2015. Facile solvothermal synthesis of $\mathrm{Zn}_{2} \mathrm{SnO}_{4}$ nanoparticles as anode materials for lithium-ion batteries. Materials Letters, 141: 255-258.

Qin, Y.L., et al., 2015. Controllable synthesis of cube-like ZnSnO3@ TiO 2 nanostructures as lithium ion battery anodes. Journal of Materials Chemistry A, 3(6): 2985-2990.

Rasoulifard, M., M.S. Dorraji, and S. Taherkhani, 2016. Photocatalytic activity of zinc stannate: preparation and modeling. Journal of the Taiwan Institute of Chemical Engineers, 58: 324-332.

Rong, A., et al., 2006. Hydrothermal synthesis of $\mathrm{Zn} 2 \mathrm{SnO} 4$ as anode materials for Li-ion battery. The Journal of Physical Chemistry B, 110(30): 14754-14760.

Shah, H.U., et al., 2018. Synthesis, Characterization and Electrochemical Properties of $\alpha-\mathrm{MnO} 2$ Nanowires as Electrode Material for Supercapacitors. Int. J. Electrochem. Sci, 13: 6426-6435. 
Shi, L. and Y. Dai, 2013. Synthesis and photocatalytic activity of Zn 2 SnO 4 nanotube arrays. Journal of Materials Chemistry A, 1(41): 12981-12986.

Shukla, A., et al., 2012. Electrochemical capacitors: Technical challenges and prognosis for future markets. Electrochimica Acta, 84: 165-173.

Simon, and Y. Gogotsi, 2010, Materials for electrochemical capacitors, in Nanoscience and Technology: A Collection of Reviews from Nature Journals. World Scientific. 320-329.

Sing, K.S., 1985. Reporting physisorption data for gas/solid systems with special reference to the determination of surface area and porosity (Recommendations 1984). Pure and applied chemistry, 57(4): 603-619.

Stević, Z. and M. Rajčić-Vujasinović, 2006. Chalcocite as a potential material for supercapacitors. Journal of Power Sources, 160(2): 1511-1517.

Stoimenov, P.K., et al., 2002.Metal oxide nanoparticles as bactericidal agents. Langmuir, 18(17): 66796686.

Tan, B., et al., 2007. Zinc stannate $\left(\mathrm{Zn}_{2} \mathrm{SnO}_{4}\right)$ dye-sensitized solar cells. Journal of the American Chemical Society, 129(14): 4162-4163.

Tan, Y.B. and J.M. Lee, 2013. Graphene for supercapacitor applications. Journal of Materials Chemistry A, 1(47): 14814-14843.

Tauc, J., R. Grigorovici, and A. Vancu, 1966. Optical properties and electronic structure of amorphous germanium. physica status solidi (b), 15(2): 627-637.

Walsh, A., J.L. Da Silva, and S.-H. Wei, 2009. Interplay between order and disorder in the high performance of amorphous transparent conducting oxides. Chemistry of Materials, 21(21): 5119-5124.

Wang, B.-Y., et al., 2015. Facile synthesis of fine $\mathrm{Zn} 2 \mathrm{SnO} 4$ nanoparticles/graphene composites with superior lithium storage performance. Journal of Power Sources, 281: 341-349.

Wang, J., et al., 2004. Synthesis, structure, and photoluminescence of $\mathrm{Zn} 2 \mathrm{SnO} 4$ single-crystal nanobelts and nanorings. Solid state communications, 131(7): 435-440.

Wang, L., et al., 2005. A simple method to synthesize single-crystalline Zn2SnO4 (ZTO) nanowires and their photoluminescence properties. Nanotechnology, 16(12): 2928.

Wang, S., et al., 2007. Coprecipitation synthesis of hollow Zn2SnO4 spheres. Materials Letters, 61(1415): 3005-3008.

Wang, T., et al., 2019. Boosting the cycling stability of transition metal compounds-based supercapacitors. Energy Storage Materials, 16: 545-573.

Wang, Y., et al., 2014. Synthesis of 3D-nanonet hollow structured Co3O4 for high capacity supercapacitor. ACS applied materials \& interfaces, 6(9): 6739-6747.

Wei, S.H. and S. Zhang, 2001. First-principles study of cation distribution in eighteen closed-shell A II B 2 III O 4 and A IV B 2 II O 4 spinel oxides. Physical Review B, 63(4): 045112.

Young, D.L., et al., 2002. Growth and characterization of radio frequency magnetron sputter-deposited zinc stannate, $\mathrm{Zn} 2 \mathrm{SnO} 4$, thin films. Journal of applied physics, 92(1): 310-319.

Yu, G., et al., 2013. Hybrid nanostructured materials for high-performance electrochemical capacitors. Nano Energy, 2(2): 213-234.

Zeng, J., et al., 2008. Transformation process and photocatalytic activities of hydrothermally synthesized Zn2SnO4 nanocrystals. The Journal of Physical Chemistry C, 112(11): 4159-4167.

Zhang, J., et al., 2015. Pre-lithiation design and lithium ion intercalation plateaus utilization of mesocarbon microbeads anode for lithium-ion capacitors. Electrochimica Acta, 182: 156-164.

Zhang, S.S., 2017. Eliminating pre-lithiation step for making high energy density hybrid Li-ion capacitor. Journal of Power Sources, 343: 322-328.

Zhang, Y., et al., 2009. Progress of electrochemical capacitor electrode materials: A review. International journal of hydrogen energy, 34(11): 4889-4899.

Zhu, B., et al., 2017. Fabrication and photocatalytic activity enhanced mechanism of direct Z-scheme g-C3N4/Ag2WO4 photocatalyst. Applied Surface Science, 391: 175-183.

Zhu, H., et al., 2006. Hydrothermal synthesis of $\mathrm{Zn} 2 \mathrm{SnO} 4$ nanorods in the diameter regime of sub-5 $\mathrm{nm}$ and their properties. The Journal of Physical Chemistry B, 110(15): 7631-7634.

Zuo, W., et al., 2017. Battery-supercapacitor hybrid devices: recent progress and future prospects. Advanced Science, 4(7): 1600539. 